CAE Working Paper \#05-03RR

Unemployment and Family-Values: A Household Distribution Sensitive Measure of Unemployment and Some Applications

by

Patrick Nolen

April 2005

Revised: November 2005

Revised: January 2006 


\title{
Unemployment and Family-Values: A Household Distribution Sensitive Measure of Unemployment and Some Applications
}

\author{
by \\ Patrick James Nolen* \\ Department of Economics \\ Cornell University \\ Ithaca, NY 14850 \\ E-mail: pjn7@cornell.edu
}

January 10, 2006

\begin{abstract}
Employment brings access to many types of benefits, both financial and psychological. Besides a wage, one can earn a sense of pride or a feeling of connection with her society or fellow employees. How attached one is to the labor market is not an issue that the usual unemployment rate deals with, though. Being unemployed one may not be able to gain access to health care, information about job openings or other non-pecuniary benefits. Knowing a person who is employed may mitigate some of this isolation but, as recent riots in France and the passing of the National Rural Employment Guarantee in India have shown, simply ignoring the issue of whether someone has access to employment opportunities is not necessarily a desirable option. Taking account of the distribution of employment across households as well as individuals is one way to deal with these issues and improve on the usual unemployment measure. In this paper I develop a new measure of unemployment, that, building on the insights of the literacy and social network literature, is sensitive to the distribution of unemployment across both households and individuals. With this class of measures characterized, I then show some empirical implications and test a main assumption used in creating the measure.
\end{abstract}

JEL Classifications: J64, D63, 047

Key Words: Unemployment, Households, Externalities, Social Networks

\footnotetext{
${ }^{*}$ I would like to thank Geir Asheim, Kuntal Banerjee, Kaushik Basu, Vidhi Chhaochharia, Tomeka Hill, Tapan Mitra and Rumki Saha for their guidance, time and help. Many thanks are also due to the participants of the Development Economics Seminar at Cornell University.
} 


\section{Introduction}

The standard way of measuring unemployment is simply to count the number of unemployed individuals in a society and divide that number by the total number of people in the labor force. Especially if the population and the size of the labor force remain unchanged, there is not much more that the standard measure of unemployment can tell us. Obviously, though, the well-being of an unemployed person depends a lot on whether she lives in a household where everybody is unemployed, or in a household where at least one person is employed. In a household with at least one employed person the unemployed individual can hope to get some benefits from the generosity of her employed family members. Even if no one shows her generosity, though, she can still enjoy the benefits of household public goods - heating, air-conditioning, better access to water, and more information about the world beyond since employed people are presumably better networked. Therefore, this connected unemployed individual is better off than the unconnected unemployed individual, the one who lives in a fully unemployed household. Furthermore, a child who lives in a household with connected unemployed individuals will be better taken care of because they too get to enjoy the public goods that being near an employed individual provides.

Measures of unemployment have been developed to account for the situation where unemployment levels remain the same but durations change over time, thus changing the burden of how unemployment is shared among the population. ${ }^{1}$ However, there seems to be little written on how to account for the household-externality aspect of unemployment. As I will show below, though, this aspect is an extremely important matter that can affect not only

\footnotetext{
${ }^{1}$ For example see Basu and Nolen (2004).
} 
well-being of an individual but also political stability and peace. Therefore, this paper is devoted to developing a new measure of unemployment that is sensitive to this 'household' aspect of unemployment.

Employment has financial and psychological benefits. Some of those benefits include monetary remuneration, access to health care, retirement benefits, access to information, a sense of pride, and a feeling of self-control. An individual that has access to these benefits can rationally predict she is better off than someone who does not have access. As recent riots in France have shown, people who perceive they lack access to many of these benefits may become disenfranchised. Access to employment along with the ability to see people with similar backgrounds as oneself employed is what gives one the ability to know that she can realistically expect that the benefits of employment are within her reach.

The usual way of looking at unemployment, as stated above, does not always capture these aspects of unemployment. That is why, to get an idea of the access to employment different groups have, its is necessary to look at the usual unemployment rate broken down by gender, race, ethnicity or one of many other observable factors. This breakdown does not get at all the aspects one may feel about her relationship to the labor market. For example, areas where the recent rioting in France has been taking place is nearly 40\%, whereas the overall unemployment rate in France is closer to $10 \% .^{2}$ Other countries, such as South Africa, have even larger disparities across different groups, though. In March of 2004 Whites had an unemployment rate of $5 \%$ and Blacks had an unemployment rate of $33 \%$ yet no riots are currently occurring and there is even less state support for Blacks in South Africa than

\footnotetext{
${ }^{2}$ These statistics are quoted from a CNN.com article entitled "Unrest Flares Amid the Curfews."
} 
immigrants in France. ${ }^{3}$

Despite the obvious and largely different cultural and historical aspects that play a major part in the current situations regarding employment in France and South Africa, one point is important to hold onto, the level of unemployment alone, even if broken down by observable characteristics, is not enough to give a full picture of how people view their employment situation. It does not account for whether one sees herself as able to access financial and psychological benefits from unemployment or if someone like herself is even capable of becoming employed in the current labor market.

Again, consider an unemployed person in two different households, one where everyone is unemployed and one where everyone but this individual is employed. Supposing neither has an indefinite amount of wealth to draw from, the former household is more likely to be in need of state support and closer to entering (if not already in) poverty. Furthermore, the unemployed individual living in a household that is otherwise fully employed means she knows that others, who share many of her characteristics, are employed and that she is capable of obtaining all the benefits that employment has to offer. A member of the fully unemployed household is enjoying no benefits that an employed individual can bring and does not necessarily know of anyone like herself who is employed or enjoying them. Therefore a measure of household unemployment, the number of fully unemployed households divided by the number of households in the economy, would more likely correlate with the view people have of their ability to financially benefit and access employment opportunities. This household level of unemployment, though, has not always followed the usual unemployment trends. Gregg and

\footnotetext{
${ }^{3}$ The unemployment rates for South Africa were calculated using data from the March 2004 South Afican Labour Force Survey.
} 
Wadsworth $(2001,2004)$ show how the difference in household unemployment and the usual measure of unemployment has varied over time for Britain and the United States. Dickens and Ellwood $(2003,2001)$ discuss how the fully unemployed households are more likely to be in poverty, rely on the state for financial support and be associated with a higher incidence of child poverty. A measure that incorporates some aspects of the household measure of unemployment may then help policy makers more fully capture how a labor market is doing in regards to supplying employment and making it accessible to different facets of society.

The consequences of one's attachment to the labor market has already been looked at in the social network literature. A social network can be thought of as an informal group of people who share social ties. These types of networks are used to informally look for jobs in the labor market, get a promotion, raise funds to start a new business or run a political campaign. ${ }^{4}$ Simon and Warner (1992) and Fernandez et al. (2000), among others, show how firms gain from using social networks when hiring workers. Calvó-Armengol and Jackson (2004) and Montgomery (1991) show, using different models embedded with social networks, how being in a good network is important and desirable to a potential employee because she will spend less time unemployed and face better job prospects if she is in a good network. A household could be considered a social network. Therefore, many of the benefits that employment brings members of good social networks can also be considered when looking at household externalities from employment.

Trying to account for the spread of benefits from employment more equitably among households has already become an issue of discussion in India. On the 21st of December

\footnotetext{
${ }^{4}$ For a review of the sociology literature on economic activity and networks refer to Smith-Doerr and Powell (2003).
} 
2004 the National Rural Employment Guarantee Bill was introduced to India's parliament and became law in $2005 .{ }^{5}$ The bill guarantees a minimum of 100 days of unemployment to specific households in India. ${ }^{6}$ In essence this bill makes the benefits from employment more attainable for people in many areas where employment was looked at as a rare state for a person to achieve or as something that one would associate with nepotism. Therefore, simply looking at unemployment as an individual concept or by breaking down the unemployment rate by district in India seemed not to be enough to address the issues of unemployment that the country wanted to address.

With the usual unemployment rate lacking the aspect of how connected one is to the labor market, the benefits that employment can bring a household and with the importance of household levels of unemployment with regards to poverty and well-being, it is important to develop a better understanding of employment and how we can more accurately capture these aspects in the measures that policy makers can use. In the next section of this paper, I lay out some axioms that are important for an unemployment measure to satisfy and explain their implications. In the third section I lay out the usual unemployment measure and provide a household effective measure of unemployment that captures the ideas discussed above. The fourth section is an empirical application of the new measure and shows how its use reranks areas of relative importance and how the employment situation of a household affects a person's probability of being employed in different periods. I conclude the discussion in the fifth section and discuss what further research can be done in this area.

\footnotetext{
${ }^{5}$ As reported on the 4th of February 2005 by The Hindustan Times. A copy NREGB can be found at http://rural.nic.in/NREGbillp.pdf.

${ }^{6}$ The article, "Reform in India: Democracy's Drawbacks," that appeared in the October 29th issue of the Economist mentions how the bill provides access to employment for households in India's poorest 200 districts.
} 


\section{Characteristics of Unemployment Measures}

When considering how to develop a measure of unemployment (hereafter MOU) that takes account of these concerns there are other literatures that provide guidance, the literature on literacy measures and social networks are two examples. Measures of literacy have been developed to account for intra-household externalities as well. In the case of literacy there are many benefits that are shared with-in the household. I will use insights from these two literatures to help account for the benefits of shared public goods, information, and even insurance that having an employed person in one's household can bring.

Employed individuals are able to bring home information about the outside world and share the benefits of employment with the other members of their household. In a closely related idea, literates can bring benefits to illiterates they live with. Literates have the ability to help people who are illiterate by reading jobs offered in the employment section of a newspaper or a literate can explain the newest farming technology one can use on her farm by reading a pamphlet. Since the work of Basu and Foster (1998), measures of literacy have been developed to deal with these types of literacy externalities. How to formalize the effect that a literate can have on an illiterate has been a point of debate, though. Basu and Foster (1998) use a constant externality whereas Valenti (2002) and Dutta (2004) allow the externality to vary based on the proportion of literate to illiterate individuals there are in a household and on the total number of literates present in a household. Mitra (2002) characterizes a class of measures that is not subject to rank reversals that the work of the above authors face with their measures. The insights that these authors bring to dealing with intra-household externality effects are useful in the realm of measures of unemployment 
as well. Therefore their contributions and insights will be cited and called upon throughout the discussion of measures of unemployment below.

Before laying out the axioms that a MOU should satisfy, the framework in which these axioms are to be formalized must be discussed. To begin, let $x=\left(x^{1}, x^{2}, \ldots, x^{H_{x}}\right)$ be an economy where $x^{h}=\left(x_{1}^{h}, x_{2}^{h}, \ldots, x_{n_{h}}^{h}\right)$ is a household with $n_{h}$ people and there are $H_{x}$ households. ${ }^{7}$ Let this economy have $n_{x}$ people, where $n_{x}=\sum_{h=1}^{H_{x}} n_{h}$. For each person in this economy, $x_{i}^{h}$, say that either person $i$ in household $h$ is unemployed, that is $x_{i}^{h}=1$, or person $i$ in household $h$ is employed, that is $x_{i}^{h}=0$. Therefore this economy contains information only about each individual's employment status and what household she belongs. While this is a very simplified concept of an economy, the framework here can easily be modified to take account of other information. If a policy maker would like to keep track of the type of employment (in a bakery or construction factory for instance) or the gender of the household member then the household vector would become more detailed, but the properties of the measures defined below would still hold. For now, though, I will stick with the simplest case, where we only know the employment status of an individual and the household she belongs to Finally, say that $\Delta$ is the set of all economies. Now I can define a Measure of Unemployment (MOU) as a mapping $M: \Delta \rightarrow R$, where $R$ is the set of reals.

If each person in a household is considered as important as each other member then an useful axiom for an MOU would be anonymity. This property says that, at least within a household, no person should be considered any different than any another. At times, though, this axiom has been modified because of concerns listed above. For example, in the context of literacy, according to Basu et al. (2002), it seems that females are more receptive

\footnotetext{
${ }^{7}$ where $n_{h}$ and $H_{x}$ are elements of $Z_{++}$, the set of strictly positive integers.
} 
than males to the benefits that living with a literate individual can provide and that living with a literate female is more beneficial to an illiterate person than living with a literate male. In the context of employment one may want to also consider these possible gender differences. For example, in this case, an employed male may be more likely to share the benefits and information he gains from employment than a female, or having the 'head of the household' employed may be more important than having any other household member employed. To make this refinement one would have to gather more information on each member of an economy, not only what household she belongs to and her employment status, but also, for example, her gender.

For use with an MOU I propose the following anonymity axiom. It is easily adjusted to take account of the issues raised above, along with many other demographic concerns that may arise.

Anonymity (A): A MOU, $M$, is said to satisfy Anonymity if, for any within household person permutation mapping, $\pi^{i}(*),{ }^{8}$ where $n_{h}$ is the same in both economy $x$ and $y, x^{h}=\left(x_{1}^{h}, x_{2}^{h}, \ldots, x_{n_{h}}^{h}\right)$, and $y^{h}=\left(x_{\pi(1)}^{h}, x_{\pi(2)}^{h}, \ldots, x_{\pi\left(n_{h}\right)}^{h}\right)$, it is true that $M\left(x^{h}\right)=$ $M\left(y^{h}\right)$.

Note that an MOU, $M$, is defined on an individual household because an individual household can simply be viewed as a one household economy.

This anonymity axiom allows an economy to be written as following. Let $r^{h}$ be the number of employed people in household $h$ and $s^{h}$ be the number of unemployed people in

\footnotetext{
${ }^{8}$ That is to say that $\pi^{i}:\left\{1,2, \ldots, n_{i}\right\} \rightarrow\left\{1,2, \ldots, n_{i}\right\}$ such that $\pi^{i}$ is one-to-one and onto $\forall i$.
} 
household $h$. Since the names of people within a household do not matter, all relevant information about a household can be written in terms of $r^{h}$ and $s^{h}$. Then an economy can be written as $x=\left(\left(r^{1}, s^{1}\right),\left(r^{2}, s^{2}\right), \ldots\left(r^{H_{x}}, s^{H_{x}}\right)\right)$ where $x^{h}=\left(r^{h}, s^{h}\right)$ is a household with $n_{h}=r^{h}+s^{h}$ people.

In order to compare economies, one economy over time or the employment situation of different geographic areas within a country it is convenient to know what is the value given to the most fully employed economy and the least fully employed economy. Consider two types of economies, $e$ and $w$. Let both economies have $H$ households and $n$ people (that is $H_{e}=H_{w}=H$ and $\left.n_{e}=n_{w}=n\right)$. Let economy $e$ be the economy that is fully employed, that is, let $e=\left(\left(n_{1}, 0\right),\left(n_{2}, 0\right), \ldots,\left(n_{H}, 0\right)\right)$. Likewise, let $w$ be the economy that is fully unemployed, or $w=\left(\left(0, n_{1}\right),\left(0, n_{2}\right), \ldots,\left(0, n_{H}\right)\right)$. Now consider the following normalization axiom.

Normalization (N): A MOU, $M$, is said to satisfy Normalization if, for any economy with $H \in Z_{++}$households and $n \in Z_{++}$people, $M(e)=0$ and $M(w)=1$.

Obviously, the normalization axiom may be modified to produce values of one's choosing for a fully employed or unemployed economy.

The next axiom, decomposability, is not without controversy. I believe that decomposability is appropriate in the discussion of unemployment, in part, because of its desirability for policy makers. To consider the axiom lets first define the concept of decomposability. I will say that economy $x=\left(\left(r^{1}, s^{1}\right), \ldots,\left(r^{f}, s^{f}\right),\left(r^{f+1}, s^{f+1}\right), \ldots\left(r^{H_{x}}, s^{H_{x}}\right)\right) \in$ $\Delta$ is decomposed into economies $y$ and $z$ if $y=\left(\left(r^{1}, s^{1}\right), \ldots,\left(r^{f}, s^{f}\right)\right) \in \Delta$ and $z=$ 
$\left(\left(r^{f+1}, s^{f+1}\right), \ldots\left(r^{H_{x}}, s^{H_{x}}\right)\right) \in \Delta$. This allows the following form of the decomposition axiom to be stated.

Decomposition $(\boldsymbol{D}):$ Let economy $x \in \Delta$ be decomposed into economies $y, z \in \Delta$. A MOU, $M$, is said to satisfy Decomposition if $M(x)=\frac{n_{y}}{n_{x}} M(y)+\frac{n_{z}}{n_{x}} M(z)$.

The main critique of the decomposability axiom is that any MOU that satisfies it rules out the possibility of inter-household externalities. For example, consider a two household economy $b=\left(b^{1}, b^{2}\right)$. By assuming decomposability the presence of the second household, $b^{2}$, has no effect on how the MOU, $M$, values the first household, $b^{1}$, or, with some abuse of notation, assuming decomposability requires that $M\left(b^{1} \mid b^{2}\right)=M\left(b^{1}\right)$. If there were interhousehold externalities then, under certain conditions, having one type of household present should changes the value that the MOU, $M$, puts on $b^{1}$. That is, ins some situations one may want to allow for the case that $M\left(b^{1} \mid b^{2}\right) \neq M\left(b^{1}\right)$. By assuming the decomposability axiom holds this cannot occur. To get around this issue one could argue that a 'household' can be interpreted liberally, as a neighborhood or social group for instance. As long as a the group boundaries can be concretely defined then the MOU presented in this paper can be modified to take account of certain inter-'household' externalities. ${ }^{9}$

Decomposition, while being debatable, has a very obvious and practical feature. It allows an economy's MOU to be written simply as the weighted sum of the MOU applied to each household in the economy. The weights implied with this decomposition axiom are simply the proportion of the number of people in the household to the number of people in the economy.

\footnotetext{
${ }^{9}$ For further discussion of the decomposition axiom and its implications please refer to Mitra (2002).
} 
Lemma 1: For any economy $x \in \Delta$ and any $M O U, M$, that satisfies $D$ that economy's MOU can be written as the weighted sum of the MOU applied to its households, that is $M(x)=\sum_{h=1}^{H_{x}} \frac{n_{h}}{n_{x}} M\left(\left(r^{h}, s^{h}\right)\right)$.

The proof of this lemma is trivial (so it is not laid out here) and requires only that the decomposability axiom be applied repeatedly.

Finally, if an economy is the same as another in every fashion except that one more person is employed in the second economy then no reasonable MOU should rank the second economy as having more unemployment than the first economy. In fact, given that more people are employed in the second economy, it beyond reasonable to say that the unemployment in the second economy is less then in the first economy. To formalize this I use the following monotonicity axiom.

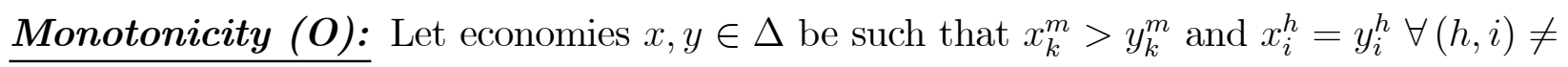
$(m, k)$. A MOU, $M$, is said to satisfy Monotonicity if $M(x)>M(y)$.

With the monotonicity and normalization axiom we now know that for any economy $x \in \Delta$, it must be the case that $M(x) \in[0,1]$.

The axioms listed above are commonly used in measures of well-being and do not place any real limit on the set of measures that can be used to look at unemployment. The set of measures that satisfy these axioms in fact include measures that both take account of externalities, see Valenti (2002) for instance, and measures that do not, the usual measure of unemployment - that will be formalized shortly - for instance. Therefore to generate a measure appropriate to concerns of employment and its externalities discussed above one 
needs to look to producing at least one other axiom that will give structure to our measure and, hopefully, fully characterize a class of measures that addresses these concerns.

\section{Effective Unemployment and Externalities}

The set of measures satisfying axioms A, N, D and O (hereafter referred to as the ANDO axioms) listed above is large and barely helpful as a starting point of where to look for a measure of unemployment that takes account of access to employment and the many benefits that unemployment brings. To begin refining the set of measures that would be desirable I look at the usual MOU and a full characterization of it.

Let the usual measure of unemployment, $U$, for any economy, $x \in \Delta$, be written as follows:

$$
U(x)=\frac{1}{n_{x}} \sum_{h=1}^{H_{x}} s^{h}
$$

Recall that $r^{h}$ is the number of employed people in household $h$ and $s^{h}$ is the number of unemployed people in household $h$. Therefore the usual MOU, $U$, is simply the proportion of the population that is unemployed. This measure is not sensitive to how unemployment is distributed across households. As long as the sum $\sum_{h=1}^{H_{x}} s^{h}$ is the same across economies or time $U$ will be constant. This measure, in the context of literacy, was fully characterized by Basu and Foster (1998) by using an indifference axiom. The indifference axiom formalized the fact that as long as the proportion of unemployed people stayed the same any MOU, $M$, satisfying the indifference axiom had be insensitive to the distribution of employment in an economy. The usual MOU, $U$, satisfies the indifference axiom. To see this, and for later discussions, consider three economies, $x, y, z \in \Delta$, such that $x=\{(0,2),(2,0)\}$, 
$y=\{(1,1),(1,1)\}$, and $z=\{(2,2)\}$. Therefore economies $x$ and $y$ both have two, twoperson households. In economy $x$ all unemployed individuals are in one household and in economy $y$ each household has exactly one employed and one unemployed individual. Economy, $z$, though, has only one four-person household with two people employed and two people unemployed. Given the network structure of labor markets and the information sharing that can take place between members of a household, one could argue that the unemployed members of economies $y$ and $z$ are at least as well off as those in economy $x$. The usual MOU does not rank these economies in that manner, though. Using $U$ all three economies are ranked the same, that is $U(x)=U(y)=U(z)=\frac{1}{2}$.

Now lets look at how to address the distributional concerns that are ignored by the usual MOU. Consider an economy with a fixed employment level and only one type of job available. Let there be a positive probability of being fired in each period and assume that social networks are used to hire employees from the labor market. Many prominent economists have used this as a starting point in constructing labor market models. ${ }^{10}$ If an employed person is working at a firm that is hiring, it is reasonable to expect she will mention the opening to any unemployed member of her household. The unemployed person could also hear of the employment opportunity through newspaper ads or other mass advertising campaigns. The point is to notice that a person in a fully unemployed household, though, only has the opportunity to hear about the job opening through the mass advertising and not through any household member. Therefore, at any given point in time, an unemployed individual who lives with an employed person is more likely to hear of employment openings than if the same

\footnotetext{
${ }^{10}$ See Simon and Warner (1992), Calvó-Armengol and Jackson (2004), and Montgomery (1991) for examples of these approaches.
} 
unemployed individual lived in a household with no employed persons. Besides information about employment opportunities the employed person can also bring home information about what type of skills are desired in the workplace. All these "employment information benefits" that an unemployed person can gain are on top off the (more important) public goods benefits that an employed person brings to the household. All this suggests that the unemployed members in the households of economies $y$ and $z$ are at least as well off as the unemployed persons in the first household of economy $x$. An MOU, $M$, that at least ranks economies $y$ and $z$ as having less unemployment than $x$, that is $M(y) \leq M(x)$ and $M(z) \leq M(x)$, would then be more appropriate in this situation.

Consider only economies $y=\{(1,1),(1,1)\}$ and $z=\{(2,2)\}$ now. While it is true that today, the two unemployed people in economy $z$ will compete for public goods, wealth and information brought home by the employed individuals, once one of the unemployed individuals gets a job, the remaining individual will now be the recipient of these benefits from three employed people. This 'long-run' consideration regarding the amount of public goods, wealth and information outweighs the 'short-run' competition for information among the currently unemployed. This is one concept raised in Calvó-Armengol and Jackson (2004) and is demonstrated with regards to employment information using some computational examples. Calvó-Armengol and Jackson (2004), though, have a very specific network model, which should not merely be compared to the colloquial concept of a household as I am doing here. With this argument, though, the unemployed people in economy $z$ can be seen as having at least as much access to public goods, wealth and information, as those in economy $y$. Therefore the unemployed in economy $z$ should be considered at least as well off as those in $y$, or $M(z) \leq M(y)$. 
Given the nature of employment externalities and the benefits that access to employment can bring, I argue that any MOU aiming to be sensitive to the distribution of unemployment across individuals and households should be designed to satisfy the following better household axiom. Beforehand, though, say that economy $y$ is created from economy $x$ by a household unemployment switch if: economies $x$ and $y$ have greater than 2 and the same number of households, $H_{x}=H_{y} \geq 2$; that each household in $x$ has the same number of employed individuals as its counterpart in $y, r^{h_{x}}=r^{h_{y}} \forall h \in\{1,2, \ldots, H\}$; that all but the last two households in $x$ and $y$ have the same number of unemployed individuals, $s^{h_{x}}=s^{h_{y}}$ $\forall h \in\{1,2, \ldots, H-2\}$; and, finally, that there is exactly one more unemployed individual in household $H-1$ in economy $y$ than in economy $x$ and one less unemployed individual in household $H$ in economy $y$ than in economy $x$, that is $s^{H_{y}-1}-1=s^{H_{x}-1}$ and $s^{H_{y}}+1=s^{H_{x}}$.

Better Household (B): Let economy $y \in \Delta$ be created from economy $x \in \Delta$ by a household unemployment switch. Any MOU, $M$, is said to satisfy the Better Household axiom if it is true that $M(x)>M(y)$ if and only if $r^{H_{x}}<r^{H_{x}-1}$.

This axiom implies that it is "better," for an unemployed person to be in a household with more employed persons. This is irrespective of how many unemployed people are present in the household. Of course this axiom is only reasonable as long as household size is within some limit. In the empirical section below I look at some of the possible implications of this axiom and how applicable it is in practice.

Using this axiom I can formalize the idea that employment is not simply a binary state but can be looked at as moving closer or further away from employment. I define the 
following effective employment value based on $x_{i}^{h}$ :

$$
p_{i}^{h}=\left\{\begin{array}{c}
0 \text { if } x_{i}^{h}=0 \\
g\left(r^{h}\right) \text { if } x_{i}^{h}=1
\end{array}\right\}
$$

Where $g(0)=1$ and $g\left(r^{h}\right)>g\left(r^{k}\right)>0$ if $r^{h}<r^{k}$. Therefore if someone lives in a household with no employed individuals and she, herself, is not employed, then her effective value is the same as her original unemployment value, one. If she lives in a household with three other individuals and is unemployed, though, her effective unemployment value is no longer one in all cases, in fact her effective unemployment value can now take the form $g(1)$ if one person in her household is employed, $g(2)$ if two people in her household are employed and so on. Therefore, when unemployed, an individual living in a four person household can take on any of the following effective unemployment values: $1, g(1), g(2), g(3)$ where $0<g(3)<g(2)<g(1)<1$. Therefore we now have a multivariate formalization of unemployment, or an effective value that we can place on the unemployment of a person within a particular household.

I will now use this formalization to define a new MOU that is sensitive not only to the level of unemployment in an economy but its distribution across households and individuals. Call this MOU the household adjusted effective measure of unemployment and define it in the following manner:

$$
M^{*}(x)=\frac{1}{n_{x}} \sum_{h=1}^{H_{x}} g\left(r^{h}\right) s^{h}
$$

This household adjusted effective MOU, $M^{*}$, satisfies axioms B, A, N, D and O (hereafter referred to as the BANDO axioms) and is actually a class of measures because different functional forms of $g$ produce different household adjusted effective MOU (hereafter referred 
to as HAE). Unlike the class of measures represented by $M^{*}$, please note that the usual MOU, $U$, however, does not satisfy the BANDO axioms. In fact, as shown in the theorem below, the class of measures defined by HAE, $M^{*}$, are the only measures that satisfy the BANDO axioms.

Theorem: A measure of unemployment, $M$, satisfies the BANDO axioms if and only if it is $M^{*}$.

Proof. To show that $M^{*}$ satisfies the BANDO axioms is trivial and will not be shown here.

Let $M$ be a MOU that satisfies the BANDO axioms.

Since $M$ satisfies axiom $\mathbf{D}$, then, by Lemma 1 , it is true that for any $x \in \Delta, M(x)=$ $\sum_{h=1}^{H_{x}} \frac{n_{h}}{n_{x}} M\left(\left(r^{h}, s^{h}\right)\right)$.

Now define $g\left(r^{h}\right) \equiv\left(1+r^{h}\right) M\left(\left(r^{h}, 1\right)\right)$; that is, $g\left(r^{h}\right)$ is the effect of $r^{h}$ people being employed on one unemployed individual in household $h$.

Let $r^{h}=0$, then $g(0)=M((0,1))=1$ by axiom $\mathbf{N}$.

Let $r^{h}>0$, then, by axiom $\mathbf{O}, g\left(r^{h}\right)=\left(1+r^{h}\right) M\left(\left(r^{h}, 1\right)\right)>\left(1+r^{h}\right) M\left(\left(r^{h}+1,0\right)\right)$. By axiom $\mathbf{N}$, though, $M\left(\left(r^{h}+1,0\right)\right)=0$ so $g\left(r^{h}\right)>0$ for all $r^{h}>0$.

Let $r^{h}>r^{k}$, then $M\left(\left(r^{h}, 0\right),\left(r^{k}, 1\right)\right)>M\left(\left(r^{h}, 1\right),\left(r^{k}, 0\right)\right)$ by axiom $\mathbf{B}$. Using axiom $\mathbf{D}$ and simplifying $r^{h} M\left(\left(r^{h}, 0\right)\right)+\left(1+r^{k}\right) M\left(\left(r^{k}, 1\right)\right)>\left(1+r^{h}\right) M\left(\left(r^{h}, 1\right)\right)+r^{k} M\left(\left(r^{k}, 0\right)\right)$. By applying axiom $\mathbf{N}$ twice, because $M\left(\left(r^{h}, 0\right)\right)=M\left(\left(r^{k}, 0\right)\right)=0$, the equation simplifies further to $\left(1+r^{k}\right) M\left(\left(r^{k}, 1\right)\right)>\left(1+r^{h}\right) M\left(\left(r^{h}, 1\right)\right)$. So $g\left(r^{k}\right)>g\left(r^{h}\right)$ when $r^{h}>r^{k}$.

Now consider economies $x, y \in \Delta$ such that $H_{x}=H_{y}=s$ and $r^{h_{x}}=r^{h_{y}}=r \quad \forall h \in$ $\{1,2, \ldots, s\}$. Let the unemployed be distributed among households as follows in economy $x=((r, s),(r, 0), \ldots,(r, 0))$, and as follows in economy $y=((r, 1),(r, 1), \ldots,(r, 1))$. 
By axiom $\mathbf{D} M(x)=\frac{r+s}{s r+s} M((r, s))+\frac{r(s-1)}{s r+s} M((r, 0))$

By axiom $\mathbf{N}$ this simplifies to $M(x)=\frac{r+s}{s r+s} M((r, s))$

By axiom $\mathbf{D} M(y)=\frac{s(r+1)}{s r+s} M((r, 1))$

Then, as an implication of axiom $\mathbf{B}$, it is true that $M(x)=M(y)$

So, with simplification, $(r+s) M((r, s))=s(r+1) M(r, 1)=g(r) s$.

Thus, for household $(r, s)$, this implies $M((r, s))=\frac{g(r) s}{r+s}$.

Plugging this into the equation for $M(x)$ and using the identity $n_{h}=r^{h}+s^{h}$ a MOU, $M$, that satisfies the BANDO axioms must have an effective employment value function $g(r)>0 \forall r>0$ such that $g\left(r^{k}\right)>g\left(r^{h}\right)$ if $r^{k}<r^{h}$ and $g(0)=1$ and must be of the form

$$
M^{*}=\frac{1}{n_{x}} \sum_{h=1}^{H_{x}} g\left(r^{h}\right) s^{h}
$$

or, another way to put it, a MOU, $M$, that satisfies the BANDO axioms must be a household adjusted effective measure of unemployment.

While this theorem limits the class of measures that satisfy the BANDO axioms solely to the class of measures defined by $M^{*}$, this is still are rather large set. Therefore, further refinements of the axioms or exploration into how the class of measures could be restricted would also be useful for policy makers and researchers.

Since any MOU that has the characteristics laid out here must be of the form $M^{*}$ it may now be useful to look at certain functional forms the effective value function can take on, or different ways of implementing $M^{*}$. Consider first why the household unemployment rate, though important to a household's dependency on the state and child poverty, does not fit into the class of measures defined by $M^{*}$. A household unemployment rate would have to give every member of the household an effective unemployment rate of zero if only one person 
in the household was employed. Therefore, for a household measure of unemployment one would set $g(r)=0$ for any $r>0$ and $g(0)=1$. This does not satisfy the properties that the effective employment value function must have. Call this measure, $M^{H H}$ and notice that while accounting for the distribution of employment across households this type of measure is callus towards the employment of individuals, unless (of course) they lived alone. Likewise, as stated before, the usual unemployment rate, $U$, while caring about individuals is indifferent to the distribution of employment across households.

The HAE measures, on the other hand, are somewhere between how $M^{H H}$ and $U$ look at an unemployed individual and the $g(r)$ function actually allows a policy maker to choose how she would like to weigh individual employment concerns against the distribution of employment across households. Furthermore, while weighing individual employment distribution and household employment distribution off against each other, the HAE measures are not simply a convex combination of $M^{H H}$ and $U$ but instead place different weights on each unemployed person depending on her household situation. Measures like this have been presented in the context of literacy by Valenti (2002) and Dutta (2004), but Dutta places the axioms on the literacy measures themselves and Valenti reaches a measure with these properties through weakening an axiom of equality which says that a society is in the best situation when the ratio of literates to illiterates is the same in each household.

To explore the usefulness of the HAE measures I look at an empirical example below and show how relative rankings of US states change and empirically examine how one could generate values for the effective employment value function and look at the better household axiom to see if there is any evidence supporting its use. 


\section{Empirical Example}

In this section I use the March 2004 Current Population Survey (hereafter CPS) to create a ranking of the unemployment levels for the 50 US states and the District of Columbia. For each state and the District of Columbia four measures are calculated: the usual unemployment rate; two HAE unemployment rates; and the household unemployment rate. The household unemployment rate, denoted as the 'HH Measure' is the percentage of fully unemployed households over the number of households that have a member in the labor force. The class of measures defined by $M^{*}$ include measures that have a strictly convex effective employment value functions. Two of these measures are used in Table 1 below. The functional form used to develop the rankings for the two HAE measures shown below is $g\left(r^{h}\right)=\alpha^{r^{h}}$ where $\alpha \in(0,1)$ and is constant. This form of the effective employment value function satisfies the required properties discussed above. In this example, $\alpha$ is set to $\frac{1}{4}$ and $\frac{3}{4}$ and the measures associated with these values of $\alpha$ will be denoted HAE .25 and HAE .75 respectively. 


\begin{tabular}{|c|c|c|c|}
\hline Usual & HAE .75 & HAE .25 & HH Measure \\
\hline 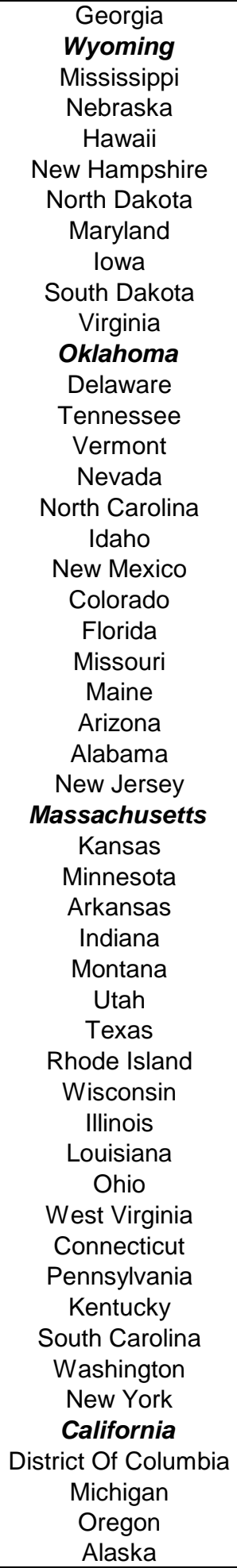 & 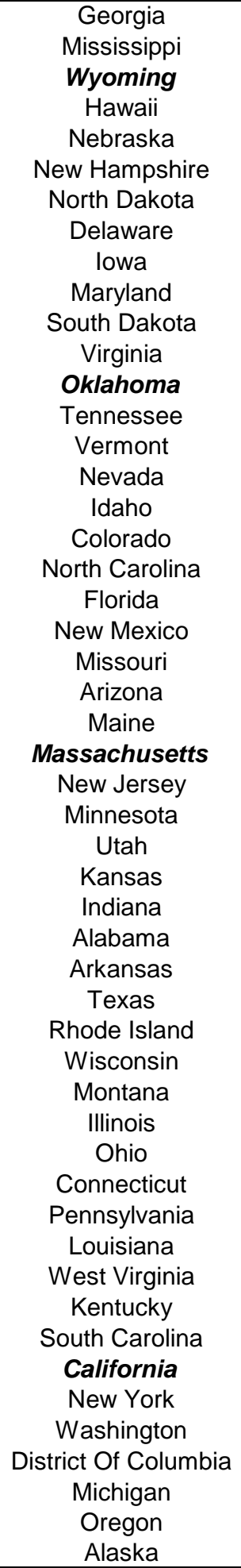 & 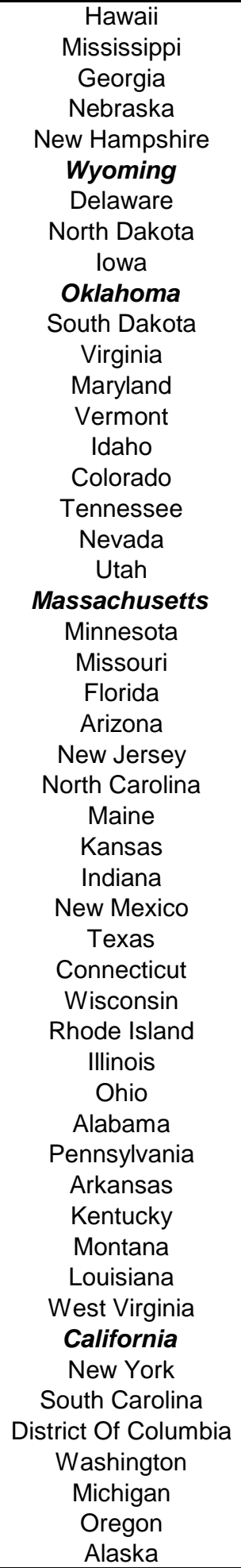 & 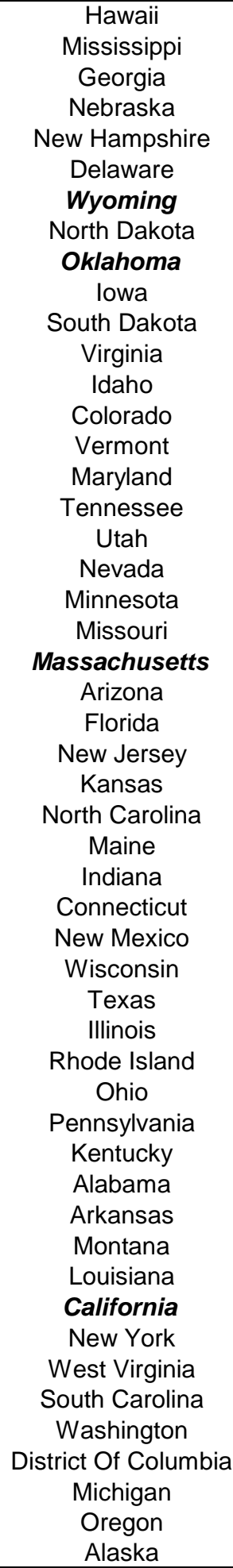 \\
\hline
\end{tabular}

Table 1:

These are the rankings of the 50 US states and the District of Columbia calcuated for four different types of measures of unemployment: "Usual" is the typical unemployment measure; "HAE .75" and "HAE .25" are the household adjusted effective MOU using an alpha value of .75 and .25 respectively. The four emboldened states show the non-montonicities that can develop with the different measures. 
Table 1 was constructed using the household indentifier and the labor force recode information included with the CPS. The table shows the 50 states and the District of Columbia listed from top to bottom. States at the top have the lowest unemployment rate according to the measure labeled at the top of the column and states at the bottom have the highest unemployment rate according to the unemployment rate labeled at the top of the column. Four states are emboldened: Massachusetts, Wyoming, Oklahoma and California. Given that the usual unemployment rate and the household unemployment rate are two extreme ways of looking at unemployment one might expect that as a HAE measure approaches one extreme or the other states may move monotonically up or down in the rankings. While this is the case with Wyoming and California, which become steadily lower and higher ranked, respectively, Massachusetts and Oklahoma show that this is not a rule. Massachusetts moves up and than back down in the rankings and Oklahoma gains and then loses ground with respect to the other states that are depicted. These non-monotonicities come from the different weights placed on the unemployed. These weights, based on the effective employment value function, are based on the employment profile of the household that each unemployed person belongs to. Therefore, the HAE measures are going to be sensitive not only to the number of unemployed individuals in each state but also to the type of household they reside in. This shows that much consideration should be given to the choice of the employment value function because the ranking will be sensitive to the form that is chosen. The choice should obviously depend on cultural, social and empirical observations.

One way to see what form of an employment value function may be appropriate for a society is to examine what empirical evidence exists on how having an employed person 
in one's household affects her ability to become employed at a certain point in the future. This is because job information is one type of benefit that knowing an employed individual brings. This type of analysis will also help examine one of the justifications for using the better household axiom - that having an employed person in one's household is beneficial in at least one aspect, the ability to find employment (due to more information about job vacancies).

To look at these two issues I present three probit regressions in Tables 2, 3 and 4 . Tables 2 and 3 show the effect of having one, two or three people employed on an unemployed person from the same household in September of 2001. The base group are people who are in households where everyone is unemployed. Note that these regressions do not control for the number of unemployed people in the household, so they are, in essence, seeing if the better household axiom is empirically justifiable with regards to employment information. Given that someone was unemployed in September of 2001, table two shows the marginal effects of being in a household with one, two or three people employed in September of 2001 on the probability of being employed four months later, in December of 2001. To look even further down the road, table three shows the marginal effects of being in a household with one, two or three people employed in September of 2001 on the probability of being employed fifteen months later, in November of 2002. All the marginal effects are positive, supporting the applicability of the better household axiom. The marginal effects of being in a household with one or two employed people are statistically significant.

The number of observations in both of these probits is not large, that is why, unfortunately, I do not control for factors such as race, overall household size or household assets. Despite these detractions the regressions show, at least on the surface, that there may be 
some empirical justification for one aspect supporting the use of the better household axiom. Likewise, table four again offers some support for the better household axiom. Table four shows that, given that someone was unemployed in December of 2001, the marginal effects of being in a household with one, two or three people employed in one's household in December of 2001 on the probability of being employed eleven months later, in November of 2002, are again all positive. The statistical significance of the marginal effects are given in the tables.

Table 2:

Probit regression on whether someone is employed in December 2001, given she was not employed in September 2001 (four months earlier)

\begin{tabular}{|c|c|c|c|}
\hline $\begin{array}{l}\text { Dependent } \\
\text { Variable: }\end{array}$ & \multicolumn{2}{|c|}{$\begin{array}{c}\text { Employed or not in Dec } 2001 \text { given person was } \\
\text { unemployed in Sep } 2001\end{array}$} & Number of Obs: 185 \\
\hline $\begin{array}{l}\text { Independent } \\
\text { Variables: }\end{array}$ & $\begin{array}{l}\text { One person employed in } \\
\text { Household in Sep } 2001\end{array}$ & $\begin{array}{l}\text { Two people employed in } \\
\text { Household in Sep } 2001\end{array}$ & $\begin{array}{l}\text { Three people employed in } \\
\text { Household in Sep } 2001\end{array}$ \\
\hline Marginal Effect: & $0.1843^{*}$ & $0.3250 * *$ & 0.1866 \\
\hline
\end{tabular}

Table 3:

Probit regression on whether someone is employed in November 2002, given she was not employed in September 2001 (fifteen months earlier)

\begin{tabular}{cccc|}
\hline \hline $\begin{array}{c}\text { Dependent } \\
\text { Variable: }\end{array}$ & $\begin{array}{c}\text { Employed or not in Nov 2002 given person was } \\
\text { unemployed in Sep 2001 }\end{array}$ & Number of Obs: 178 \\
$\begin{array}{c}\text { Independent } \\
\text { Variables: }\end{array}$ & $\begin{array}{c}\text { One person employed in } \\
\text { Household in Sep 2001 }\end{array}$ & $\begin{array}{c}\text { Two people employed in } \\
\text { Household in Sep 2001 }\end{array}$ & $\begin{array}{c}\text { Three people employed in } \\
\text { Household in Sep 2001 }\end{array}$ \\
$\begin{array}{l}\text { Marginal Effect: } \\
\text { * Significant at 5\% level }\end{array}$ & $0.1471^{*}$ & $0.1990^{*}$ & 0.1206 \\
\hline
\end{tabular}


Table 4:

Probit regression on whether someone is employed in November 2002, given she was not employed in December 2001 (eleven months earlier)

\begin{tabular}{|cccc|}
\hline $\begin{array}{c}\text { Dependent } \\
\text { Variable: }\end{array}$ & $\begin{array}{c}\text { Employed or not in Nov 2002 given person was } \\
\text { unemployed in Dec 2001 }\end{array}$ & Number of Obs: 168 \\
$\begin{array}{c}\text { Independent } \\
\text { Variables: }\end{array}$ & $\begin{array}{c}\text { One person employed in } \\
\text { Household in Dec 2001 }\end{array}$ & $\begin{array}{c}\text { Two people employed in } \\
\text { Household in Dec 2001 }\end{array}$ & $\begin{array}{c}\text { Three people employed in } \\
\text { Household in Dec 2001 }\end{array}$ \\
$\begin{array}{cccc}\text { Marginal Effect: } \\
\text { * Significant at 5\% level }\end{array}$ & $0.1413^{*}$ & 0.0974 & 0.1511 \\
\hline
\end{tabular}

Using the tables above one could begin to suggest an effective employment value function for the US economy during this period. For example, if a policy maker were interested in how to value an unemployed person's current state then she could set $g(1)=1-0.1843=0.8166$ and $g(2)=0.675$. Using enough regressions and time periods a policy maker could develop a better empirical estimate of how she may want to value an unemployed person is a specific type of household. Of course, a policy maker could also use her experience, intelligence or any other insights she may have to choose the form of the effective value function without the need to turn to the data. Given how the relative rankings changed so much in Table 1, though, it is clear that a decent amount of thought should be used in setting the effective employment value function.

\section{Conclusion}

Unemployment does not only effect an individual. It effects her household, how she perceives herself and the opportunities and information that she has available to her. In countries that lack much state support or where unemployment is concentrated in specific households, unemployment can lead to, or become a catalyst for, unrest and the disenfranchisement of 
certain groups or peoples. This aspect of detachment is not captured solely by looking at the usual unemployment rate broken down by regional or demographic characteristics. This is because employment and its benefits are earned not only by being employed, but also through being connected to the labor market. These connections to employed individuals and the outside world bring such important benefits as better access to water, heating, cooling and information from the world outside of one's household. This type of connection is captured by the household adjusted effective unemployment measures. Furthermore these measures are sensitive not only to the distribution of unemployment across households, but also to the level of individual unemployment in a society.

The unrest in France and the unemployment issues facing such countries as South Africa and India are both examples of how employment and the attachments to its benefits are important for members of a particular nation. India has already adopted a policy that directly deals with these issues in its National Rural Employment Guarantee Bill. Some of the issues that India is addressing in this bill are formalized in the HAE measures above. These policy related examples are not the only issues suggesting that the HAE measures are an appropriate way to further our understanding of the labor market. The social network literature has already shown us how the connection that one has to informal networks can lead to better employment situations or lower drop out rates. Therefore, one strand of literature already being used among labor economists provides a natural motivation for looking at the HAE measures of unemployment.

In the empirical section of this paper, after being fully characterized, the household adjusted effective MOU is shown to have a large effect on the relative rankings when applied to US states and the District of Columbia. It does so by treating unemployment no longer as 
binary but as multivariate, where the weight placed on an unemployed individual depends on which household she resides in. Household unemployment has been shown to have strong correlations with poverty and other measures of wellbeing and the household adjusted effective measures capture this relationship by giving incorporating sensitivity to the distribution of unemployment across households. The last part of the empirical section sketches how one could empirically estimate the effective value function and provides justification for the better household axiom. Therefore, with the importance of how unemployment is distributed across individuals and households and the empirical suggestion that the better household axiom is justifiable, the household adjusted effective measures of unemployment capture the fuller picture of employment that is presented in this paper. 


\section{References}

BAsu, K., And J. E. Foster (1998): "On Measuring Literacy," The Economic Journal, 108, 1733-1749.

Basu, K., A. Narayan, and M. Ravallion (2002): "Is Literacy Shared Within Households? Theory and Evidence for Bangladesh," Labour Economics, 8, 649-665.

Basu, K., And P. Nolen (2004): "Vulnerability, Unemployment and Poverty: A New Class of Measures, Its Axiomatization and Applications," BREAD 2004 Working Paper, No. 069.

Calvó-Armengol, A., And M. O. Jackson (2004): "The Effects of Social Networks on Employment and Inequality," The American Economic Review, 94(3), 426-454.

CNN (2005): "Unrest Flares Amid the Curfews," Retrieved November 9, 2005, from http://edition.cnn.com/2005/WORLD/europe/11/09/france.riots/index.html.

Dickens, R., And D. T. Ellwood (2001): "Whither Poverty In Great Britian and the United States? The Determinants of Changing Poverty and Whether Work Will Work," NBER Working Paper 8253.

_ (2003): "Child Poverty in Britain and the United States," The Economic Journal, 113, F219-F239.

Dutta, I. (2004): "Generalized Measures of Literacy," Mathematical Social Sciences, 48, $69-80$. 
Economist (2005): "Reform in India: Democracy's Drawbacks," printed October 27th, pp. 23-26.

Fernandez, R. M., E. J. Castilla, and P. Moore (2000): "Social Capital at Work: Networks and Employment at a Phone Center," American Journal of Sociology, 105(5), $1288-1356$.

GregG, P., and J. Wadsworth (2001): "Everything You Ever Wanted to Know About Measuring Worklessness and Polarization at the Household Level But were Afraid to Ask," Oxford Bulletin of Economics and Statistics, 63, 777-806.

(2004): "Two Sides to Every Story: Measuring the Polarisation of Work," CEP Discussion Paper No. 632.

Hindustan Times (2005): "Standing Committee on Rural Development Inivtes Suggestions on National Rural Employment Guarantee Bill, 2004," Published February 4.

Lok SABha (2004): "National Rural Employment Guarantee Bill," version introduced on Dec 21st, http://rural.nic.in/NREGbillp.pdf.

Mitra, T. (2002): "On Literacy Rankings," CAE Working Paper 02-16.

Montgomery, J. D. (1991): "Social Networks and Labor-Market Outcomes: Toward an Economic Analysis," The American Economic Review, 81(5), 1408-1418.

Simon, C. J., And J. T. Warner (1992): "Matchmaker, Matchmaker: The Effect of Old Boy Networks on Job Match Quality, Earnings, and Tenure," Journal of Labor Economics, 10(3), 306-330. 
Smith-Doerr, L., And W. W. Powell (2003): "Networks and Economic Life," Working Paper, http://people.bu.edu/ldoerr/Networks.

Valenti, P. (2002): "Should We Be Concerned About the Distribution of Literacy Across Households? An Axiomatic Investigation," CAE Working Paper 02-15. 